\title{
Biosynthesis of Copper Oxide Nanoparticles and Its Antimicrobial Activities
}

\author{
K. Buvaneswari*, R. Revathy \\ PG Department of Chemistry, Sri S. Ramasamy Naidu Memorial College (Autonomous), Sattur - 626 203, Tamilnadu, India.
}

\section{ARTICLE DETAILS}

\section{Article history:}

Received 07 July 2018

Accepted 12 July 2018

Available online 22 July 2018

\section{Keywords:}

Copper Nanoparticles

Phyllanthus amarus Extract

Antibacterial Activity

\begin{abstract}
A B S T R A C T
An environmental friendly approach is employed to synthesize copper oxide nano particles. In the present study copper oxide nanoparticles were synthesized using plant extract of Phyllanthus amarus (kelanelli). The synthesized nanoparticles were characterized using XRD, FT-IR and SEM to understand the structural and morphological characteristics of the copper oxide nanoparticles. The XRD results show that the average crystalline particle size was found to be $26.8 \mathrm{~nm}$ and from SEM studies it was found that these nanoparticles exist in cubic structure. $\mathrm{CuO}$ nanoparticles have much potential against the pathogens like Pseudomonus sp., E. coli and Trichoderma sp., etc.
\end{abstract}

\section{Introduction}

The synthesis of metal oxide is of much interest to the scientific community because of their wide range of applications. Generally nanoparticles are synthesized by variety of chemical and physical methods which are quite expensive and hazardous to the environment which involve use of toxic chemicals that are responsible for various biological risks. The synthesis of nanoparticles via green route does not employ toxic chemicals. Thus the advantage of green synthesis of nanoparticles is a key branch of nanotechnology. The production of nanoparticles using plant extract has drawn significant interest recently because of its rapid, cost effective, ecofriendly, non-pathogenic and providing a single step method. Different type of nanoparticles have come up but copper nanoparticles have proved to be most effective and has good antimicrobial efficiency against various micro-organisms, The copper oxide nanoparticles are important class of semiconductors which have applications in many fields [1]. Currently different methods have been utilized to produce nano crystalline copper oxide such as sonochemical [2], hydrothermal [3], microwave radiations [4], sol gel technique [5], solid state reaction [6], electrochemical [7], vapour deposition [8], electrochemical reduction [9] radiolysis reduction [10], and chemical reduction of copper metal salt [11-13] etc. In the present study copper-oxide nanoparticles were synthesized using plant extract of Phyllanthus amarus mainly effective against jaundice, a liver damage in human beings.

\section{Experimental Methods}

$\mathrm{AR} \mathrm{CuSO}_{4}$ was purchased from Merck and it was used without any purification. All the glasswares has been washed with distilled water and dried using a hot air oven before use. Fresh leaves of Phyllanthus amarus have been collected from Kovilpatti.

\subsection{Plant Extract Preparation}

Freshly collected Phyllanthus amarus leaves were shad dried and powdered. $0.5 \mathrm{~g}$ of the powdered sample were boiled for $10 \mathrm{~min}$ in $100 \mathrm{~mL}$ sterile distilled water and filtered through Whatmann No. 41 filter paper. The filtrate was further filtered through $0.6 \mu \mathrm{m}$ sized filter paper. The filtrate was used for the present work.

\subsection{Green Synthesis of Silver Nanoparticles}

As typical process, $1.0 \mathrm{mM} \mathrm{CuSO}{ }_{4}$ solution was added to sodium hydroxide solution and the plant extract at $1: 1$ ratio for $10 \mathrm{~min}$ at $80{ }^{\circ} \mathrm{C}$ The whole mixture was stirred for 40 minutes. The turning of light brown colour solution to pale green precipitate indicated the formation of $\mathrm{CuO}$ nanoparticles. The phyto-constitutents present in the plant extract helps in the reduction and stabilization of $\mathrm{CuO}$ nanoparticles. The contents were washed using double distilled water thrice. The sediments were collected and dried in an air oven and calcinated at $400{ }^{\circ} \mathrm{C}$ for 2 hours $[14,15]$. The final product was characterized through XRD, IR and SEM to get details about the prepared nano particles.

\section{Results and Discussion}

\subsection{Characterization of CuO Nanoparticles}

The IR spectrum of $\mathrm{CuO}$ nanoparticles have shown band at 451.34 $\mathrm{cm}^{-1}, 422.41 \mathrm{~cm}^{-1}$ and $482.20 \mathrm{~cm}^{-1}$ corresponding to metal-oxide band. The peak observed at $3300 \mathrm{~cm}^{-1}$ which can be assigned to the $-\mathrm{OH}$ stretching of water. The $\mathrm{C}=0$ stretching at $1662 \mathrm{~cm}^{-1}$ was shifted to a higher wave number at $1645 \mathrm{~cm}^{-1}$ due to interaction of copper nanoparticles. The characteristic peaks in the range of $1741.72 \mathrm{~cm}^{-1}$ confirms the aromatic unsaturation $(\mathrm{C}=\mathrm{C})$ of stabilized kelanelli system. The presence of (C-O) bond was assigned by the peaks found at 1201$1157 \mathrm{~cm}^{-1}$. The other peaks indicated that presence of some metabolites in the plant extract.

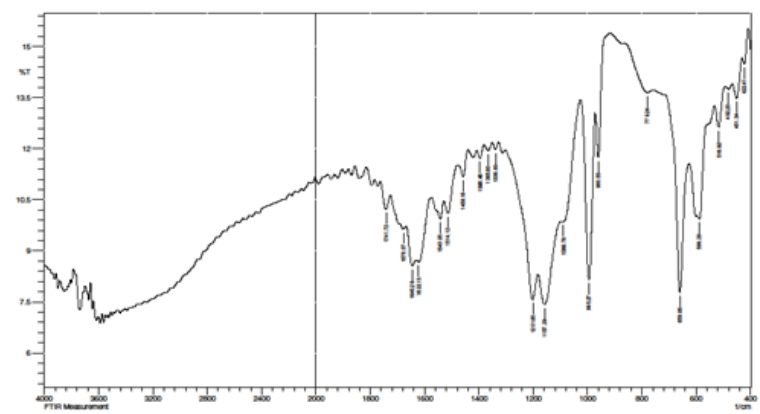

Fig. 1 FT-IR spectrum of $\mathrm{CuO}$ nanoparticles

The crystalline size of material was tested using XRD powder diffraction method and the size was calculated by using Scherrer's equation. 


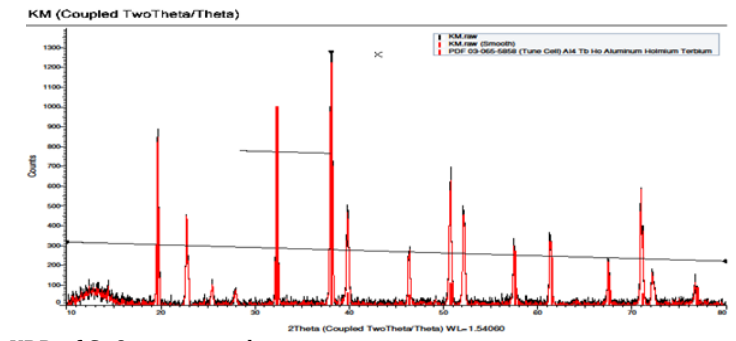

Fig. 2 XRD of $\mathrm{CuO}$ nanoparticles

The above figure shows XRD pattern of synthesized copper nanoparticles using a leaf extract of Phyllanthus amarus. The average crystalline size of the synthesized copper oxide nanoparticles was found to be $28.68 \mathrm{~nm}$ using Debye Scherrer's equation. The XRD peak shows a high crystalline of copper sample level with diffraction angles of $32.312^{\circ}$, $38.087^{\circ}, 19.622^{\circ}, 51.626^{\circ}$ and $62.486^{\circ}$ which correspond to the characteristic face centered cubic (FCC) of copper lines indexed at (202), (110), (103), (450) and (113) respectively.

Morphology of synthesized copper nanoparticles was characterized by SEM analysis and shown in Fig. 3. It can be view that the copper nanoparticle formed well dispersed and evenly distributed in all direction. SEM images of the those compounds have shown very clear that most of the particles are cubic morphology of material.

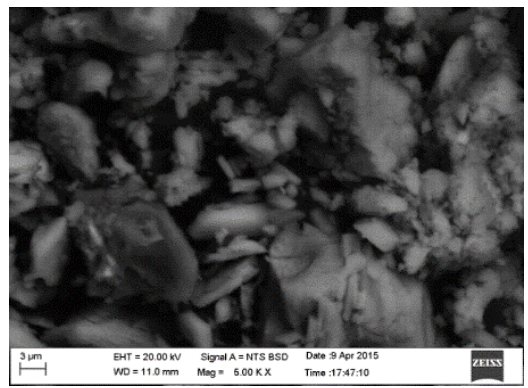

Fig. 3 SEM image of $\mathrm{CuO}$ nanoparticles
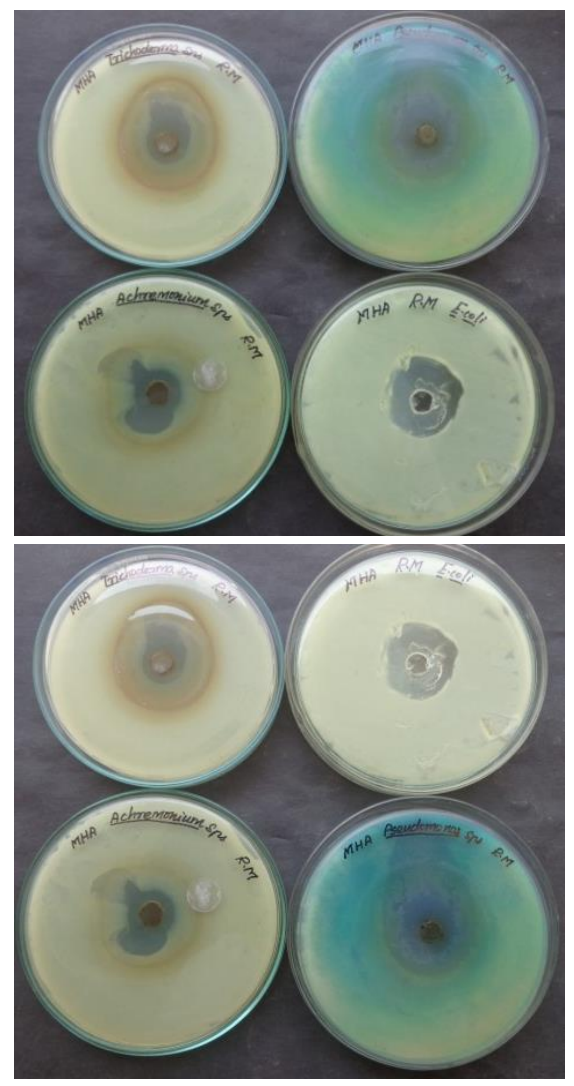

Fig. 4 Antibacterial activity of extract against bacterial pathogens

\subsection{Antimicrobial Activity}

The agar well diffusion method was used to study antibacterial property of synthesized $\mathrm{CuO}$ nanoparticles using MHA. The $\mathrm{CuO}$ nanoparticles showed efficient antimicrobial property due to their extremely large surface area which provide better contact with pathogens such as Staphylococcus aurous (gram positive), E. coli and Pseudomonas $s p$. (gram negative). The ZOI values against the respective cultures were given in Fig. 4 and the values were noted in Table 1. The result indicated that ZOI of Pseudomonas sp., Staphylococcus sp. and E. coli were found to be $29 \mathrm{~mm}, 24 \mathrm{~mm}$ and $28 \mathrm{~mm}$ respectively. Like that the antifungal activity of $100 \mu \mathrm{L}$ of DMSO extract against Candida sp., Achremonium sp. and Trichoderma sp. shows the activity of $18 \mathrm{~mm}, 21 \mathrm{~mm}$ and $32 \mathrm{~mm}$ respectively.

Table 1 Antimicrobial study of $\mathrm{CuO}$ nanoparticles

\begin{tabular}{lc}
\hline Organisms & Concentration of extract and zone of inhibition (mm) \\
\hline Pseudomonas sp. & 29 \\
Staphylococcus $s p$. & 24 \\
E. coli & 28 \\
Candida sp. & 18 \\
Achremonium $s p$. & 21 \\
Trichoderma sp. & 32 \\
\hline
\end{tabular}

\section{Conclusion}

$\mathrm{CuO}$ nanoparticles were successfully synthesized using Phyllanthus amarus extract. The results indicate that the synthesised $\mathrm{CuO}$ nanoparticles were compact, uniform and consist of cubic morphology with diameter about $28.68 \mathrm{~nm}$. The functional group present in leaf extract has been confirmed by FT-IR. The biomolecules present in the leaf extract were mainly responsible for the reduction of $\mathrm{CuO}$ nanoparticles. The result manifested that $\mathrm{CuO}$ nanoparticles possessed a better antimicrobial activity.

\section{References}

[1] M.J. Guajardo-Pacheco, J.E. Morales-Sanchez, J. Gonzalez-Hernandez, F. Ruiz, Synthesis of copper nanoparticles using soybeans as a chelant agent, Mater. Lett. 64 (2010) 1361-1364.

[2] R.V. Kumar, R. Elgamiel, Y. Diamant, A. Gedank, J. Norwig, Sonochemical preparation and characterization of nanocrystal in copper oxide embedded in poly (vinyl alcohol) and its effect on crystal growth of copper oxide, Langmuir 17 (2001) 1406-1410.

[3] X. Zhang, G. Wang, X. Liu, Different CuO nanostructures: synthesis, characterization, and applications for glucose sensors, J. Phys. Chem. C Nanomater. Interf. 112 (2008) 16845-16849.

[4] H. Wang, J.Z. Xu, J.J. Zhu, H.Y. Chen, Preparation of $\mathrm{CuO}$ nanoparticles by microwave irradiation, J. Cryst. Growth. 244(1) (2002) 88-94.

[5] A.A. Elise, A.V. Lukas kin, A.A. Vertegel, L.I. Heifets, A.I. Zhirov, Y.D. Tretyakov, Synthesis and characteristics of copper nanoparticle, Mater. Res. Innov. 2000 (2010) 308-311.

[6] J.F. Xu, W. Ji, Z.X. Shen, Preparation and characterization of CuO nanocrystals, J. Solid State Chem. 147 (1999) 516-519.

[7] Borgohain, J.B. Singh, M.V. Rama Rao, T. Shripathi, S. Mahamuni, CuO: Synthesi and characterization, Phys. Rev. 61 (2000) 11093-11095.

[8] C. Hyungsoo, P. Sung-Ho, Seedless growth of free-standing copper nano wires by chemical vapor deposition, J. Am. Chem. Soc. 126 (2004) 6248-6249.

[9] H.H. Lin, C.Y. Wang, H.C. Shih, J.M. Chen, C.T. Hsieh, Characterizing well-ordered $\mathrm{CuO}$ nanofibrils synthesized through gas-solid reactions, J. Appl. Phys. 95 (2004) 5889-5892.

[10] S.S. Joshi, S.F. Patil, V. Iyer, S. Mahumuni, Radiation induced synthesis and characterization copper nanoparticles, Nanostru. Mater. 10 (1998) 1135-1144.

[11] N. Aruldhas, C.P. Raj, A. Gedanken, Synthesis, characterization, and properties of metallic copper nanoparticles, Chem. Mater. 10 (1998) 1446-1452.

[12] H. Hashemipour, M.E. Rahimi, R. Pourakbari, P. Rahimi, Investigation on synthesis and size control of copper nanoparticle via electrochemical and chemical reduction method, Int. J. Phys. Sci. 6 (2011) 4331-4336.

[13] R. Vijaya Kumar, R. Elgamiel, Y. Diamant, A. Gedanken, Sonochemical Preparation and characterization of nanocrystalline copper oxide embedded in poly (vinyl alcohol) and its effect on crystal growth of copper oxide, Langmuir 17 (2001) 1406-1410.

[14] J. Huang, Q. Li, D. Sun, Y. Lu, Y. Su, X. Yang, et al., Biosynthesis of silver and gold nanoparticles by novel sun dried Cinnamomum camphora leaf, Nanotechnol. 18 (2007) 105104-105108.

[15] H.J. Le, G. Lee, N.R. Jang, J.H. Yun, J.Y. Song, B.S. Kim, Biological synthesis of copper nanoparticles using plant extract, Nanotechnol. 1 (1999) 371-374. 